\title{
Brand Narration and Fashion Films
}

\author{
Simonetta Buffo \\ Università Cattolica del Sacro Cuore and Istituto Marangoni, Milan, Italy
}

\begin{abstract}
Starting from the new approaches of brand communication in New Millennium Era, we show why, according to us, the fashion film is a powerful tool in defining and strengthening the visual identity of a fashion brand. Our analysis is focused on ordering the different kinds of narration in this special category of on-line videos and we discover that they work about the three fundamental parameters of the Visual Identity Model.
\end{abstract}

Keywords: fashion film, brand narration, branded contents, video on line, native advertising

\section{The New Communication Panorama}

Brand communication has been showing signs of major and radical changes since the late 90s', when it became clear and prominent that the past communication format was rapidly becoming outdated.

The convergent forces, which led to this trend, can be summarized in three main points:

(1) The first is the growing advertising crush on the traditional media, resulting in increased costs and competition, while at the same time decreasing the consumer's attention. In fact, the latter is increasingly worn out and intolerant of the continuous advertising blitz, thus developing new defence tools.

(2) The second refers to the consumer himself who, in the postmodern era, claims with increasing strength and incisiveness his active role in the branding process in any market, demanding the acknowledgement of the individuality from the brands.

(3) Last but not least, the massive spread of new media, which contributed to make the brand and individual-consumer relationship more democratic, rebalancing the importance and impact of both: Internet allows any brand to directly listen to its public, without mediations of any kind, and any individual can turn himself into an influencer in the buying process. We might even say that more and more often the individual-consumer is able to dictate his own wishes and somehow impose them on the brand.

All these forces the brands to review the way they face the market. As far as especially concerns the communication, the brand starts being aware of the changes in the way people communicate with each other and now brands have to adapt to harmoniously fit in the new contexts: especially with the mobile, the users are constantly connected and make use of any type of content in a completely different context. According to kpcb.com website, in 2015 the time spent on mobile devices exceeded that spent on desktop.

The role of the advertising communication has also partially changed: advertising has always been parasitic, yesterday as today. In the past, however, it tried to exploit the attention of the medium user, for example interrupting him while reading a newspaper or viewing a TV program, which is why there was talk of advertising breaks and the approach used was that of interruption marketing. We still find today on TV

Simonetta Buffo, Academic, Faculty of Communication and Sociologic Studies (COMeS), Department of Sociology, Università Cattolica del Sacro Cuore and Istituto Marangoni. 
advertising break slots, but the adverts often have a very low duration (up to 7 seconds), to fit in the program in the least disruptive way possible and expecially to prevent the viewer from making the decision to change channel. The well-known zapping phenomenon is, in fact, the viewer's defence weapon against the traditional media old logics of the interruption marketing.

Today, however, the advertising trend is camouflaging itself within the medium that hosts it, blending itself with the other contents and adjusting its format to the hosting medium. In social media, for example, brands are developing formats that perfectly fit into the environment that hosts them: doing so, the Internet user who scrolls his Facebook page finds advertising formats that don't invade the spaces, because they respect the vertical orientation and don't interrupt the flow (or scroll). This form of advertising is what is called native advertising: brand contents become part of the publisher's content.

Native advertising as a form of brand contents promotion is something more than traditional advertising, even because brands are consistent with the context they operate in, not only for their format but especially contents.

Market professionals and branding scholars are today theorising new strategic approaches that acknowledge the brand need to structure its own strategies more on the branded contents than products: when it comes to experiential marketing, brand entertainment and branded contents, this refers always to this new approach to brand imagery.

Each of these strategies has abandoned the goal of capturing the attention of its own consumer, with the awareness that our attention threshold is getting lower, while stimuli are increasingly numerous: a research carried out by the Statistic Brain Research Institute states that from 2000 to 2015 our concentration has lowered from 12 to 8.5 seconds, meaning that now it is slightly lower than that of a red fish ( 9 seconds).

Therefore, the brands aim is to produce engagement with its interlocutor: thrilling, intriguing, amusing become the levers that marketing has to use.

In Your Brand. The next Media Company (2013), Michael Brito emphasizes the importance for the brand to become "publisher", constantly producing new branded contents, authentic, valuable, meaningful contents, able to offer stimuli that go beyond the commercial logics and allow the interlocutor (that was once seen as target) an active role in building up the brand world. We are talking about communication actions where the brand renounces to endow its product with the role of protagonist, though building up a world that is the pillar around which the entire strategy revolves: engagement thus becomes a continuous process, working on cognitive, emotional and behavioural aspects of its own public, far from the traditional advertising logics that aimed to "hit" its own public to affect their mind, to manipulate their decisions persuading them to buy. Just to be clear: we are not affirming that the brand has abandoned today its own business goals in favour of "ethical" values in the social fabric, as if it were an ONLUS. Brand goals are still the same, but to reach them the must is going through different paths, meeting the postmodern individual-consumer on a congenial ground for him.

\section{Videos and Fashion Films}

Among the new tools available for the brands to create new contents and entertain their public there are online videos.

According to the American website eMarketer.com, in 2015 Americans spent an hour and a quarter of their time online to see these videos and ZenithOptimedia for the same year states a +23 growth in online videos consumption on desktop compared to the previous year, but the growth index is even $+44 \%$ on mobile 
devices. Additionally, from a research carried out by Nielsen emerges that online advertising videos generate a higher recall than TV advertising videos.

In fact, online videos are not to be confused with the classic commercials: if the explicit goal of the latter has always been promoting the branded product sales, the online videos offer entertainment, information or just emotional contents aiming to engage the Internet user and make it possible for him to participate in the promotion of himself, under the typical web sharing logics. If the public perceived some advertising intent in these videos, the high risk would be to be skipped. Today's commercial communication needs to be able to camouflage itself better and make itself almost invisible.

The online videos made by brands are therefore using more and more complex narrative strategies, inspired more by the cinematographic world than that of the classic advertising: the speed logics runs counter to that of the story-telling, where the brand appears discreetly.

This opens new brand narrative universes, much more complex, where the consumer is welcomed and enabled to explore new fantastic dimensions and meet the brand in an apparently random manner.

This approach is like another brand communication tool, the product placement, a technique through which the brand agrees with a film production company to appear inside a movie. This technique was born almost simultaneously with cinema: one of the first movies of the inventors of the Seventh Art, the Lumiere brothers, is "La partie de cartes" (1895) and portrays three men playing a game of cards, showing in plain view on the table a beer bottle produced by the father-in-law of one of the two brothers. After that, precisely in 1896 Lumière brothers also collaborated with Francois-Henri Levanchy-Clarke, Europe's representative of the manufacturing company of soaps "Lever Brothers", with the goal of producing and distributing their movies also in Switzerland in exchange for appearances of "Lever Brother" soap in their movies: it happened for example in the movie Washing day in Switzerland (1896). Remember that Lever Brothers was an English company producing soaps and detergents that, in 1930, became Unilever, which today has more than 400 brands in the hygiene and home products, as well as in food and drink sector.

The goal of the product placement has always been to exploit the fascination that the viewers experience from the movie, inserting a brand that could thus become itself the object of fascination.

In this respect, online videos work in the same way, with the same goal: the difference is that in the case of product placement the screenplay is already defined and the brand has to fit in it, often coexisting with other brands, whereas in the case of online videos the narration of the brand world is staged to create a show that thrills emotions. This highly "entertainment" nature of the videos leads them to record the highest growth rates in recent years, reaching $+10 \%$ of the total investments in Internet advertising (ZenithOptimedia-2015).

Facebook has recently modified the newsfeed algorithm, in order to facilitate the display and upload of videos, that is the stream of personal contents: in just six months there has been a growth from 1 billion video views per day in the third quarter of 2014 to 4 billion in the first quarter of 2015 , of which $75 \%$ on mobile (Internet Trends 2015 - Code Conference, KPCB, May 2015).

The Hire is one of the first shorts produced by a brand for the network that meets these features: in fact, the German automaker BMW has produced since 2001 a short film saga for the network. Eight episodes where different filmmakers interpret the experience lived by the driver-protagonist (Clive Owen) while he accompanies unusual and often bizarre characters on this car.

The filmmakers involved are among the most famous in Hollywood: John Frankenheimer, Ang Lee, Wong Kar-Wai, Guy Ritchie, Alejandro Inarritu, John Woo, Joe Carhnan, Tony Scott. 
One of the most famous is certainly the one directed by Guy Ritchie and interpreted by Madonna, where she plays the role of the capricious and unkind celebrity: the driver wants to wreak revenge on this despotic celebrity and therefore he pretends to do a car chase and he proceeds with a quite imprudent and reckless driving, which forces the celebrity to roll continuously inside the car. Arrived at the destination, the woman is thrusted out the car on the red carpet, in front of the photographers and crowd of fans, showing her slouch and embarrassed.

All these videos adopt the typical language of the action movies: the nominal normality is interrupted by some events, such as a complication that must be solved by the driver, car chases in the city jam, sudden shootings, suspense fuel the mystery that is then dissolved at the end of the movie. So the car takes on the role of a magic tool (using Propp's terminology), owned by the protagonist and allowing him to brilliantly overcome any obstacle. The driver's skills are therefore assisted, better to say emphasized by the car, which reflects the brilliant character of the man: there is a kind of continuous contamination between the protagonist's and brand's personality. We can then ascertain that, in this saga, the narrative structure still evokes the old advertising logics: using the product of a specific brand becomes possible to acquire some qualities and perceive oneself in a new way.

Brand communication had to change also these contents over these years because the consumer imposed it on the brand: today's consumer living in the Consumption Society is an expert, critical consumer, no longer willing to believe that the brand is a sort of superhero with super powers, able to turn a toad into a prince.

Moreover, in the postmodern era the individual strongly claims his individuality. Consumption is also a moment with the goal of gratifying its own uniqueness and loses a huge part of the social value it had in the last century. This consumer rejects the past clustering, those old lifestyles that tended to standardize consumers in homogeneous groups for habits and values, passions and hobbies, exposed to the aspirational model of perfection proposed by the brand and achievable with that precise brand, the unique key to access the well-being.

One of the markets that best seems to have understood this need for a sudden change is the fashion market, offering new ways of communicating, even in the content.

In fact, fashion has been the first market to communicate its own right to be oneself as its basic value, thus correctly interpreting what the postmodern individual felt and wanted to hear. The today's goal of fashion is personalizing and interpreting: the garment is the expression of a way of feeling and being, which is not rigidly defined and codified by the fashion images only, but fashion returns the typical eclecticism of the new millennium. Just as the fashion images, whether static or dynamic, which reproduce a world where everything is possible and everyone is accepted. The concept of beauty is also experiencing an era of great transformations, becoming relative and more and more personalised: we are not talking about the Beauty in fashion, but many different types of beauty.

Since the beginning of the new Millennium, fashion has developed new types of messages concerning the contents, producing new techniques and showing its ability to use new technologies with a greater eagerness and strength than other markets.

Among these news, we certainly consider fashion films, shorts with very particular features compared to the most of the other online videos, and so particular to give birth to a new category with its own name. Additionally, in all the main fashion cities in the world we find Fashion Film Festivals. There are at least 4 today considering only London, of which the first in absolute was organised by Central Saint Martins in 2006, 
Fashion in Film; the second city that hosted this event was Paris, with ASVOFF, organised by the fashion designer and blogger Diane Pernet, and a festival that has today achieved its ninth edition. These are both international events, involving professionals from the world of fashion and art in general, famous photographers who experiment the new tools and young filmmakers.

Fashion films have developed their own language (net-aesthetics), creating brand imageries and becoming strategic tools to build up the visual identity of fashion brands and, whether they are fashion films with a narrative plot or fashion films without an authentic plot aiming only to create empathy with the viewer, in both cases we consider fashion film as a powerful tool for building up the visual identity of the fashion brand, crossing the boundaries of the brand entertainment.

As mentioned by N. Kahn (2012), in his article Cutting the Body: Why fashion image is no longer still (pp. 235-250).

(...) images of fashion are not simply a vehicle of consumption relying on the discourse of commodity fetishism, as is the case with fashion advertising. Instead one could argue that fashion film aims to break down boundaries between consumption and representation, by relying on cinematic language. This implies that fashion film no longer merely depends on the illusionary concealment of the creation of value through the spectacle of the image, but offers the spectator an aestheticization of voyeurism. This is particularly apparent through the use of narrative in fashion film, which implies a shift from the viewer as consumer to the viewer as spectator.

In short, in front of the fashion film the viewer's expectation is playful because the brand intends to promote free pleasure, both aesthetic and emotional, for all those who want to share that experience.

Our belief is that in fashion films the brand voice is present in different ways, showing clearly identifiable brand imageries, just because they work on the visual identity of the brand itself.

\section{Narrations and Fashion Films}

This is in fact what we want to understand: how fashion films work as brand identity building tools. Fashion film often looks like pure entertainment, offered by the brand to the internet user in Internet, and this is also the reason why fashion films are one of the best solutions of brand entertainment. On the other hand, however, we are aware that the only goal of the brand is to generate business in every initiative it undertakes, so even the fashion film has to be a branding tool working on the brand visual identity, because it needs to be a good investment for the company.

The strength of this form of communication is precisely the great opportunity it offers to narrativize the brand world, to turn the communication into pure suggestion and entertainment, far from the purely commercial purposes, albeit only apparently. But how these narrativized contents become branded contents?

The ambitious goal we have is therefore to rationalize what was born not to be rationally understood by the interlocutor: in fact, images bypass the conscious to reach and stimulate the unconscious and irrational part of individuals. When analysed, a kind of violence or forcing is committed. On the opposite, however, in order to read the language of the images, as it is for any type of language, it is first necessary to decodify them and then proceed in the search for meaning.

Adopting a semiotic approach, coming from that branch of semiology applied to the cinema headed by C. Metz (1931-1993), after analysing the languages of fashion films (in the previous article), we now try to understand what types of narratives are implemented in these particular short-movies.

We specifically want to understand now what aspects the brand can focus on to narrativize its own world. 
We start with the choice of the term narration, as a mostly ordered exposition of facts. In classical rhetoric, narration (Latin narratio, Greek $\left.\delta \eta^{\prime} \gamma \eta \sigma ı \zeta\right)$, was the part of the speech following the preamble with the purpose of orderly display the fact, which was told focusing on the selection and combination of the events in order to be effective in front of the public. The choice of this term, and the no longer used story-telling, is due precisely to this reason: referring to the speeches of the classical era, we intend to ascertain exactly which main points are exposed to the interlocutor, which aspects stand out specifically and which ones are instead touched lightly or overlooked and why. In classical era, narration was an important aspect to measure the orator's skills, as conclusions depended on them. In our case we will understand what is the order through which the branding topics are chosen to detect the decisive aspects for the viewer's involvement.

Narration is therefore comparable to the design of a building: it's a matter of finding that subtle balance created between functionality (for the brand) and pleasure (for the consumer).

Narration corresponds to the events structure, the choice of their sequence, even when there is not a true story and, in this case, the images work on the interlocutor's imagery, offering new experiential brand dimensions.

In our analysis, only those videos where the protagonist is the brand imagery have been considered, meaning that videos such as interviews or back-stages have been excluded because they are considered to have a strong informative and often promotional component of the brand: There are many videos in Internet that show the brand know-how in manufacturing the product or videos where the designer tells about his own style choices. These are extremely useful videos for the brand because they use the network as a powerful tool for spreading information: the consumer uses Internet for entertainment, and we have already underlined it, but also to get information and be able to research and compare products before purchasing. The online video is therefore very effective even as an informative tool.

Our object of study is, however, very different videos from the latter because we believe that fashion film should be considered as that video aiming at the creation of an experiential brand dimension in a brand entertainment logics.

From many fashion films, what stands out is that there are three types of narrative choices:

(1) Telling a story.

(2) Drawing a personality.

(3) Creating an atmosphere.

In the first case, telling a story, the film unfolds in events or simply in situations lived by the protagonists and narrated in a logical sequence: the images progression (the editing choice) or the voiceover help to interpret what is seen. The viewer's attitude is therefore active, very similar to that of the viewer of any film or TV series, regardless from the type of language used: the viewer tries to understand what he sees, sometimes rationally and consciously and sometimes irrationally, simply identifying himself with the character who interprets a certain way of feeling or living. This type of fashion film is a tour inside the brand identity building: the brand itself guides the vision, helping the viewer to orient himself.

These are in fact brand narratives with a narrative plot, that is one main theme around which the entire video revolves and reveals a crucial aspect of the brand identity. These fashion films work on the key concept of the visual identity, that symbolic and value concept that contributes to define the brand experiential world. If brand identity is defined by the marketing work choosing the strategic levers to act on and is a kind of box where all the elements making the brand unique and distinctive are contained, the key concept is instead choosing 
what the brand considers appropriate to communicate in a precise social and market moment, related to the tactical or strategical goals and the context the brand acts in, in order to build up a unique and distinctive visual identity.

In the saga created by Giorgio Armani for the eyewear collection Frames of life, for example, the best international schools of cinema are invited to test their students in a contest to produce a fashion film about the new GA eyewear collection, that is a short film telling about the world seen wearing Giorgio Armani eyeglasses, focusing on those aspects of everyday life that have been always belonged to the brand value universe.

There are also cases where, although the will of the brand to tell a story is clear, the communication is still cryptic, thus resulting complex in understanding completely the message of the fashion film. Take a look at those recently proposed by Kenzo, for example: it's not simple to understand what is the meaning of the story, although it's equally clear that we are seeing a short film that intends to communicate a content, using unconventional film languages and narrative structures.

For example, in the last film Cabiria, Charity and Chastity (2017/2018) by Natasha Lyonne, the characters are theatre performers: decisively human aspects of the characters' personality are highlighted, such as fragility, insecurity, fear of being rejected, their own emotions and feelings, in a continuous game between representation and reality: and we don't certainly know if the characters on stage represent themselves of their theatrical fiction.

Each viewer can therefore interpret the film story in absolute freedom. The language used massively refers to art films and the most evident reference, even in the title, is to the Italian film Le notti di Cabiria by Federico Fellini (1957): the moment when the protagonist, Cabiria, this sweet and fragile Roman prostitute, goes on the stage and the audience teases her, provoking her uneasiness and embarrassment, reminds us feelings and sensations showed in the fashion film by Kenzo. In addition to that, the name of the clown school (La strada), the mask worn by one of the characters of the fashion film, the situation comedy and the type of story are clear references to another film by F. Fellini (1954) La strada, once again played by Giulietta Masina, a film that in 1957 won the Oscar as best foreign film.

In Kenzo's Fashion Film (Figure 1), not all characters with their actions are easy to understand, meaning that several interpretations can be attributed and they are all legitimate. What is clear in my opinion is the main theme or key concept around which the entire narrative path revolves, which we can summarize with the expression the circus of life, exactly as in Fellini's films, where joy and sadness, loneliness and cheerfulness alternate in an infinite windmill.

This leads me to say that these fashion films (as well as some online brand videos in other merchandising sectors, such as the saga Hire by BMW) are the most interesting brand communication, because it is the most innovative and far from the traditional brand narrations. It's a way of communication close to the Cinema intended as an Art form, free expression of an artist-director who wants to display his own point of view, in a critical, subjective and interpretable manner.

This is hardly surprising because, assuming the consumer's perspective, we have already mentioned the figure of this new prosumer, active producer of contents (brand contents, if he wants). Many fashion films are therefore more complex to interpret, without sometimes a true "end" to the story, because they evidently want to allow the interlocutor to complete and possibly end the story. 
Considering the fashion brand perspective, fashion films that recall so strongly the cinema art and art films are the signs of a current trend of the new Millennium, which pushes the luxury brand of the fashion market to get closer to art in all its forms and expressions. And evidently also to the Seventh Art. The Antonio Marras' SS 2018 fashion show, for example, is openly inspired by the woman (Federico Fellini's wife) and actress Giulietta Masina. And there are copious examples.

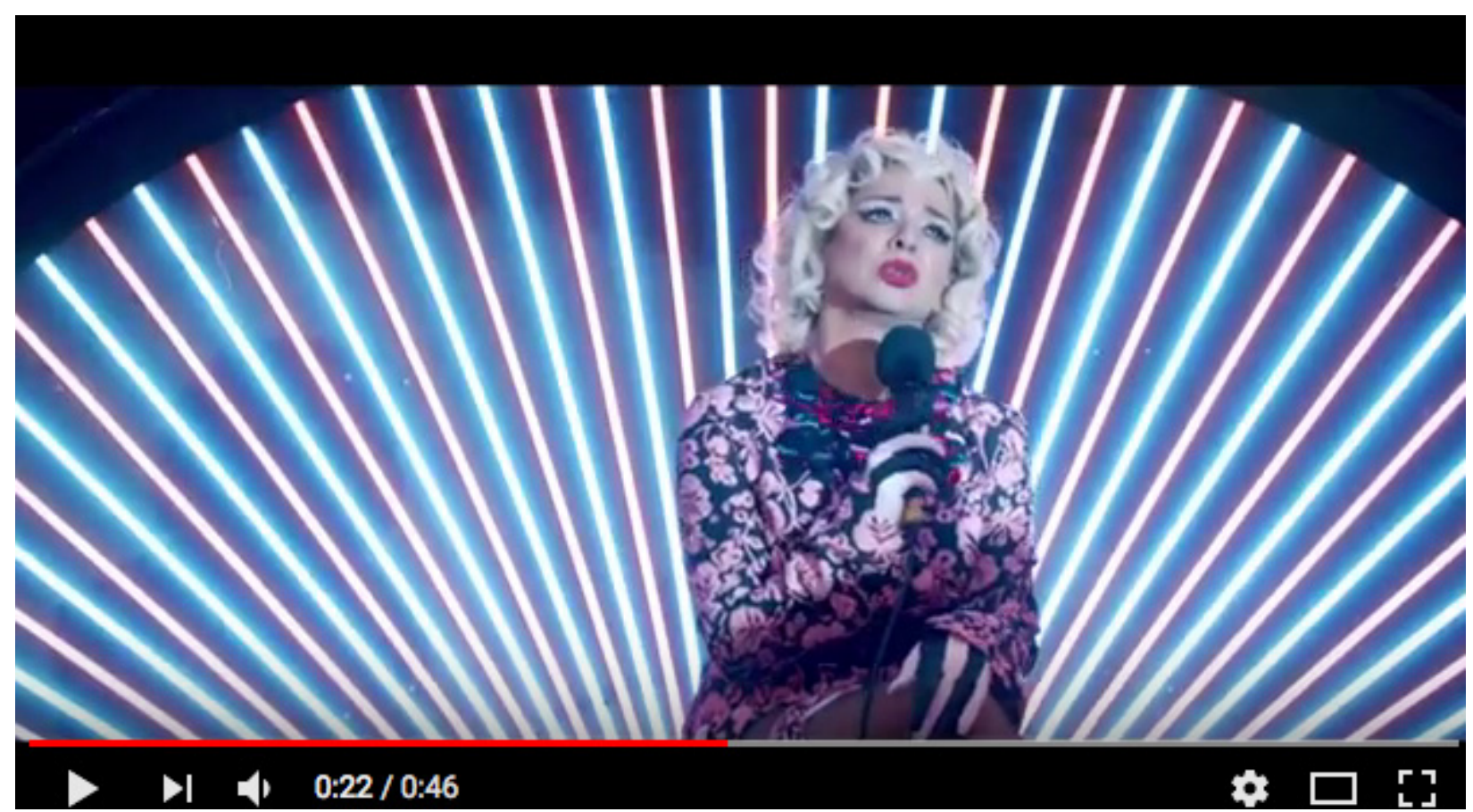

Figure 1. Kenzo FW 2017-2018, Cabiria, Charity, Chastity by N. Lyonne.

Moving to the second case, drawing a personality, we register the presence of fashion films that focus on an individuality, a character of the protagonist: when there are events or situations, these are functional to show the path of a specific personality (of woman), and therefore they don't necessarily follow a clear logical sequence setting up cause-effect relationships between facts, but rather preferring to temporize on aspects of this woman, showing the sensitivity or a distinctive aspect of the woman-muse of that brand.

We know that brands in the new Millennium had to deal with a consumer difficult to define, whose identikit is elusive. The important Qualitative and Quantitative Research Institute Eurisko talks about "fast moving consumer", that is a multimedia, fast consumer and unpredictable in his behaviours, able to create an opinion in his social reference basin. The most evolved brands have therefore launched the "strategy of complicity", which Umberto Eco treated in 1972 (Lector in fabula): the empirical enunciator who is outside of the message and produces it. The brand therefore projects onto the text both its image and the image of its own receiver. The more the communication adopts language and contents close to those to whom it is directed, the more the strategy of complicity is effective.

In the fashion market, the brand often deals with its public as the only possible interpretation (original and often avant-garde) of an identity, or even just an aspect of a personality. In Gucci clothes created by Alessandro Michele we often find a sort of Millennials, that is alternative, bohemian and free young people the designer refers to, as well as the intellectual, modern and unconventional woman interpreted in the Maison Prada clothes. 
But obviously not just in clothes. The communication also contributes to tell the public about the fashion brand. And some films draw the figure of the Muse or Ideal Consumer of the brand in question.

An example may be the Prada fashion film Past Forward (Figure 2), by the award-winning American director David O. Russel. The narration focuses on the dreams of three different women, who however live similar emotions and therefore enter into the same dreamy dimension, developing the same themes. From a first intuitive reading of this communicative choice, we infer that these women represent almost all women, regardless from their skin colour, socio-demographic clusters and lifestyles they have.

The story begins showing the three different women: they all look elegant, wearing formal clothes, maybe business clothes, and each one of them individually enters in the same building that is strongly modern, refined and styling. After that, each one of them comes back to her own room and gives us the idea of a futuristic situation, with object similar but at the same time revolutionary compared to those we currently use. The timeline seems that of a near future.

Each woman receives a phone call on her transparent mobile and we understand it's not a good news, which causes headache in each of them, who therefore go to bed and start sleeping.

The three dreams are identical and only the protagonist changes, becoming in turn each one of the three girls alone. What is narrated seems to be the fears of any woman: initially each of them is in the same space, maybe an airport and maybe they are leaving, but other two unknown women, without shoes, observe and inspect without discretion nor reserve, as perhaps only women know how to do with other women. The protagonists are uncomfortable, go to show their documents to the officials in uniform but immediately begin to escape and are therefore followed by the officials and the two previously mentioned women, and each of the three women seems frightened and tired. During the escape there is a random encounter, each woman with a different man: the editing slows down the frames sequence and the filmic time expands, giving centrality to this moment. Then the escape resumes and each girl is reached by the officials, there is a fight and all the girls are left on the ground, wounded, in the darkness. At this point the man of the previous encounter appears, stretching his hand and helping them to get up. Each couple arrives in a medical clinic to treat the wounds, but we discover that doctors don't have the mouth on their faces. The moment of terror is interrupted by the arrival of one of the two women seen at the beginning of the film, who strangles the doctor. Each couple continues running until each one arrives in a large hall and each man and woman starts dancing, until they fall exhausted to the floor to then wake up by the sea. Now each woman wakes up and then the three women, in turn, go out from the building they had entered in and we see each woman first alone and then accompanied by their men in the dream. They are all in pairs and smile, when also the two initial women appears, who seem to be a couple by themselves. The last frame is however devoted to the thoughtful face of each of the three protagonists. It is again important to underline that, before each couple starts dancing in the dream, each protagonist looks at his own partner and the images immediately go fast to show us the memories of the past boyfriends with whom there was happiness at the beginning and then, when the relationship ended, despair.

In this twelve-minute fashion film, therefore, Prada shows us the woman with her fears through the eyes of the director O. Russell: the fear of being observed by other women, of being persecuted, with the awareness that only a stretched hand can help in lifting her up again, especially if it's the hand of her own partner, but contemporarily there is the fear that the love story could end and lead to despair. This Prada woman especially shows her desire to react and go on in any case, with the certainty that she will continue to fight but with the hope of not being alone. Here too, quotations are strong, here represented by the clearly Hitchcock inspired soundtrack: 
for the entire short film, except for a slight interruption and deviation in the dancing moment, the soundtrack recalls that of the film Marnie (1964), focused entirely on the dual personality of this woman (Tippi Hedren) and the drams that she lived during her childhood, which strongly affected her balance and psyche. It will be the stretched hand of a man (Sean Connery) to save her from herself and her fears.

In the case of Past Forward, the central theme is therefore not focused on the brand identity but on the personality of its own Muse, with her own fragility and strength: the protagonist is the "lector in fabula" by U. Eco, who is here instead defined as "ideal consumer", using the branding terminology.

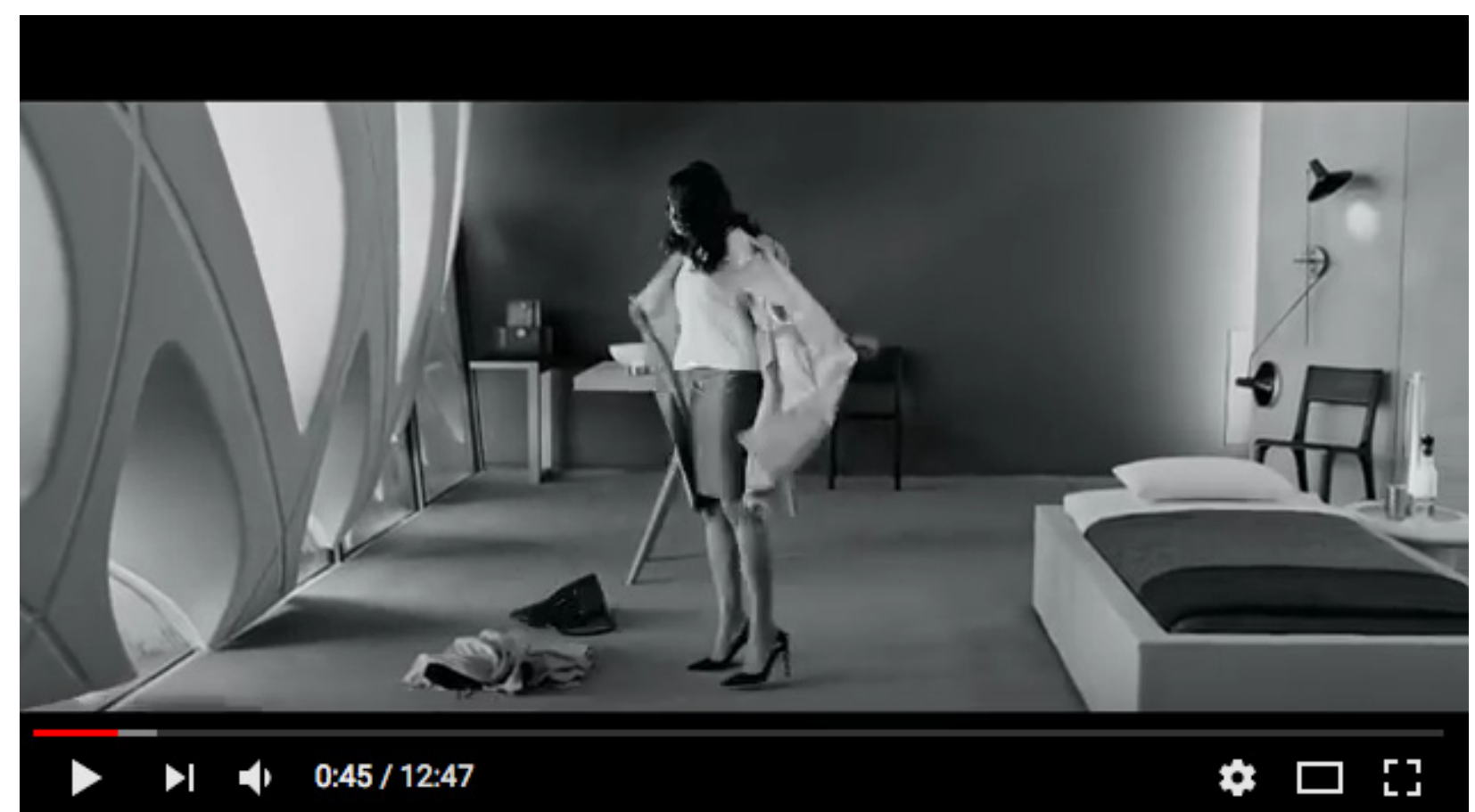

Figure 2. Prada 2016, Past Forward by D.O. Russell.

The third type of proved narration is when the brand works on creating an atmosphere.

In this type of fashion film, there is no ordered sequence of events, which are translated into meaning (or content) by the editing and voiceover. We neither have the impression to see a well-defined personality profile of woman or man. What the narration focuses on is rather the mood, which is generally the faithful translation of the brand style, meaning that suggestion that a fashion brand is able to create which is translated into filmic codes. In this atmosphere created by the brand, the consumer is invited to enter in to share it.

An example is the recent fashion film made by $H \& M$, the famous fast fashion brand. It's not surprising that a fast fashion brand uses one of the most common tools used in the luxury market: we have already seen that fast fashion brands, even in their communication, tend to emulate the choices made by other brands in the same sector (fashion), but on a luxury level.

In the fashion film "80s Nostalgia in Tokyo", Fall 2017, the absolute protagonist is the leisure: we witness a series of women different by age and nationality, including Naomi Campbell, who sing joyful in a video projected in one of the many karaoke places in Tokyo, where the men present don't express a great happiness. We can't say there is a narrative plot supporting the video, nor a particular kind of woman is drawn, also because these would be discordant with the H\&M audience, that is completely transversal. The viewer is 
instead projected into this contagious joyful and festive atmosphere, on the notes of a famous Wham song of 1983 "Enjoy what you do", that is a cheerful invitation to enjoy in what you do and if you don't enjoy, then you have to stop doing it. In short, H\&M is fun.

Another interesting example is the fashion film made by Steven Klein for Alexander McQueen, SS 2014: in this short, the protagonist is a very blond-haired Kate Moss, with short hair, while she walks alone in the deserted streets of a metropolis, as New York could be. The woman seems to be chased and filmed by a man, maybe a stalker, with a camera in his hands, that she seems to recognize at first, or at least at the beginning of the film she turns her gaze to the camera, as if she were looking at him fearless. The woman then reaches her home and here something happens, but we don't know what: images show us an alternation of the protagonist's gazes who first seems worried and then terrified, with light flashes alternated to dark moments. Maybe the man followed her. Maybe the man wants to hurt or kill her, but nothing confirms or denies this interpretation. The music and sounds that accompany the video vision are the typical thriller sounds, such as the person's isolated footsteps, the breath, the squeak of a door, the noise of a camera that continues to shoot in the vacuum. We don't know exactly what happens, but the atmosphere wants to create discomfort and anxiety, and even fear of this male figure (or simply this camera), who follows and snoops the protagonist in a nocturne, cold, civic environment, where she is absolutely alone. The atmosphere is definitely dark: the colours, environment, feelings inspired by the video accompany a kind of unsolved foreboding. And all this reminds the world of Alexander McQueen.

Also in this case, the fashion movie is a quotation from the film world: we talk about the cult movie "Peeping Tom" (1960), directed by the English Michael Powell, whose protagonist is a filmmaker, Mark Lewis, a voyeur with a real obsession for snooping the others.

The movie is a psychological thriller, that shows the unsolved childhood problems of this man who would like to become a director, but in the meantime takes raunchy photos for a magazine. Driven by his voyeuristic obsession, he will become a serial killer who kills the young women he snooped with his camera. The film focuses often on the women who will later become the man's victims: the camera therefore becomes a detective eye, which wants to capture and film these women's emotions. What is however most interesting for Mark is the feeling of fear, as well as his father, when he was a child, analysed and used him as a guinea pig, stimulating the fear in him and preventing him from growing up quietly. And this lack of serenity can be also the synthesis of the sensations stimulated by the Alexander McQueen's fashion movie we mentioned before.

Great examples of this third type of narration are also many fashion films made by Nick Knight and his Showstudio.com (Figure 3): for the FW 2016 of the Japanese brand Comme de Garcon, Nick Knight made a fashion film where garments are shown in a continuous flow of images, deconstructing and reassembling them in pixels for the entire video, which lasts about two minutes. Nick Knight, using the tools offered by the new technologies, manipulates images, decomposes them in pixels to convey an idea of perpetual motion, even in its stillness.

The suggestion he creates is linked to a futuristic world, a world designed by The Matrix (Larry and Andy Wachowski, 1999), that world that "has been put in front of our eyes to hide the reality", a world where real and virtual have cancelled their boundaries to merge into a single new dimension. And clothes take on an unexpected depth, becoming almost super-tech bas-reliefs on our desktop. 


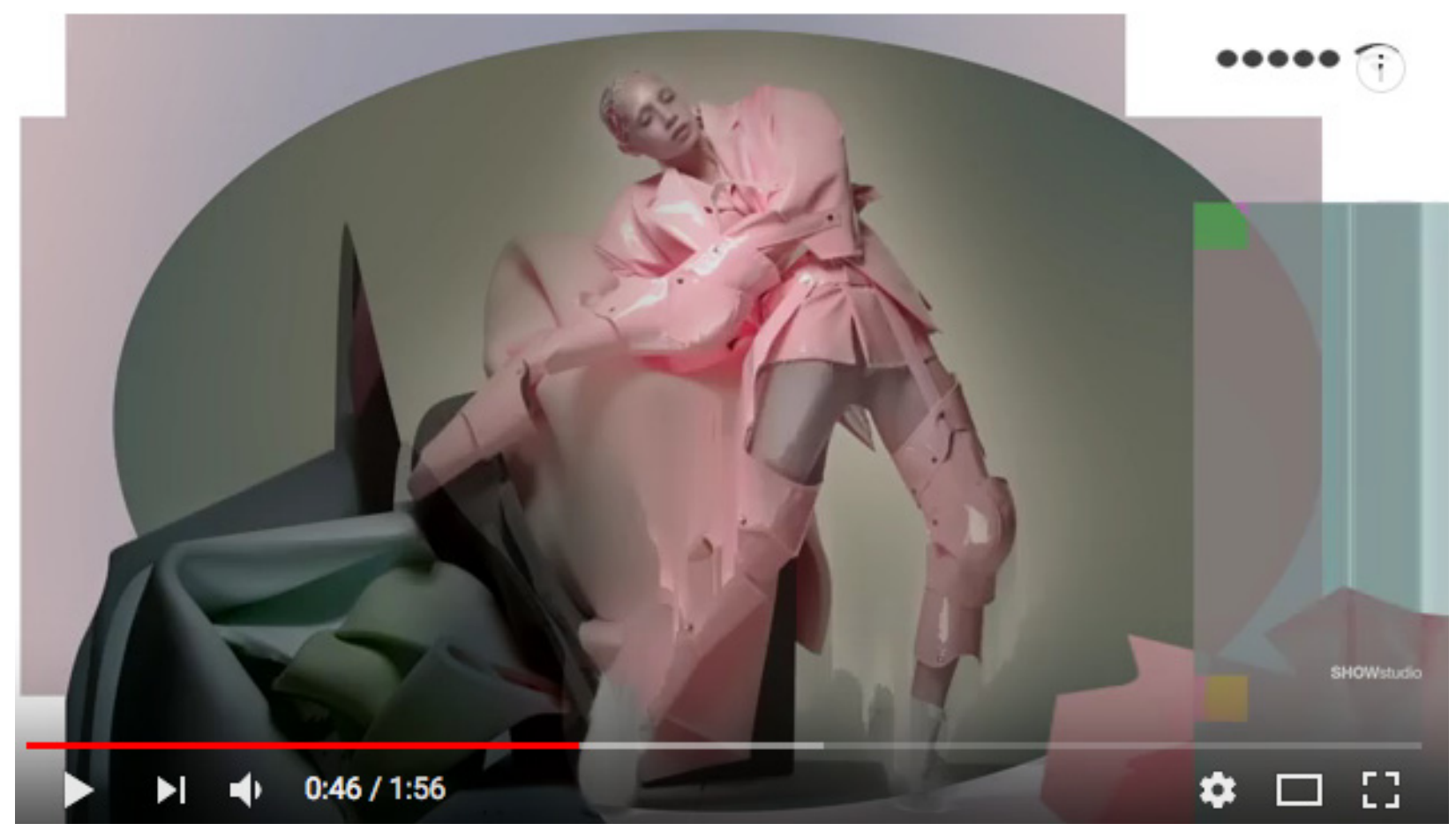

Figure 3. Comme de Garcon FW 2016-2017, by Showstudio.

In conclusion, fashion film is a powerful strategic tool, first of all because it engages viewer but also because it works defining and strengthening the visual identity of fashion brand: telling a story, drawing a personality and creating an atmosphere get stronger key concept, consumer and mood of the brand, the parameters of the Visual Identity Model (Figure 4).

The others on line videos, like back-stages or interviews, brand communication is connoted too, of course; but only in fashion film the goal is relating to brand experience definitely, raising emotions in receiver; and emotions last during the time among people, that share them (also thanks to social media).

In this way fashion film reaches new objectives in terms of branding process.

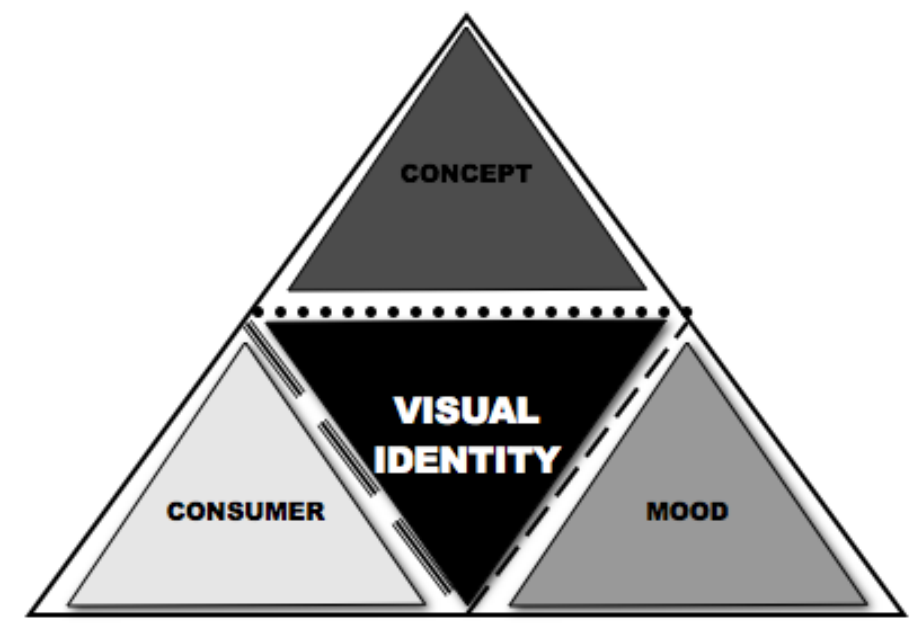

Figure 4. The Visual Identity Model (2012). 


\section{References}

Aaker, D., \& Joachimsthaler, E. (2009). Brand leadership. London: Simon and Schuster.

Brito, M. (2013). Your Brand, The Next Media Company: How a social business strategy enables better content, smarter marketing, and deeper customer relationships (Que Biz-Tech). QUE Indianapolis USA.

Buffo, S. (2012). Modalità espressive del fashion advertising (Expressive modalities of fashion advertising). Franco Angeli Editore Milano-Italy.

Buffo, S. (2016). Fashion Films and Net-Aesthetics. Journalism and Mass Communication, 6(7), 409-419.

Codeluppi, V. (2012). Ipermondo (Hyperworld). Laterza editore.

Escalas, J. E. (2009). Self referencing and persuasion: Narrative transportation versus analytical elaboration. Retrieved from http://citeseerx.ist.psu.edu/viewdoc/download?doi=10.1.1.320.1271\&rep=rep1\&type=pdf

Fabris, G. (2003). Il nuovo consumatore: verso il post-moderno (The new consumer: Towards the post-modern). Franco Angeli Editore Milano-Italy.

Kapferer, J. N., \& Bastien, V. (2010). The luxury strategy: Break the rules of marketing to build luxury brands. London: Kogan Page.

Khan, N. (2012). Cutting the fashion body: Why the fashion image is no longer still. Fashion Theory, 16(2), 235-250.

Kotler, P. (2016). Marketing 4.0. Hoboken, New Jersey: John Wiley \& Sons, Inc.

Propp V. (1968). Morphology of folktale (2nd ed.). University of Texas Press.

Smith, M. (2017). The native advertising advantage. McGraw-Hill Education - Europe.

Uhlirova, M. (2013). 100 Years of the Fashion Film: Frameworks and Histories. Fashion Theory, 17(2), 137-158.

Vogler, C. (2007). The writer's journey. Michael Wiese Productions. 